Published in final edited form as:

ACS Sens. 2016 October 28; 1(10): 1244-1250. doi:10.1021/acssensors.6b00452.

\title{
In vitro Detection of Hypoxia using a Ratiometric Quantum Dot- based Oxygen Sensor
}

\author{
Armen Shamirian, Hamid Samareh Afsari, Asra Hassan, Lawrence W. Miller, and Preston T. \\ Snee* \\ Department of Chemistry, University of Illinois at Chicago, 845 West Taylor Street, Chicago, \\ Illinois 60607-7061, United States
}

\begin{abstract}
A quantum-dot based ratiometric fluorescent oxygen probe for the detection of hypoxia in live cells is reported. The system is comprised of a water-soluble near-infrared emissive quantum dot conjugated to perylene dye. The response to the oxygen concentration is investigated using enzymatic oxygen scavenging in water, while in vitro studies were performed with HeLa cells incubated under varying $\mathrm{O}_{2}$ levels. In both cases a significant enhancement in dye/QD emission intensity ratio was observed in the deoxygenated environment, demonstrating the possible use of this probe for cancer research.
\end{abstract}

\section{Abstract}

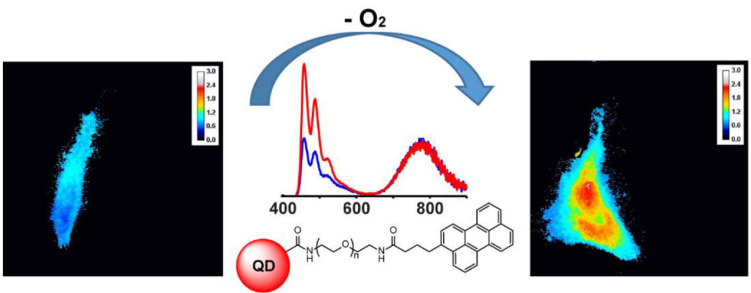

\section{Keywords}

quantum dot, nanocrystal; fluorescence; perylene; hypoxia; cancer marker

Molecular oxygen plays a vital role in a broad range of chemical and biological reactions. ${ }^{1}$ While reactive oxygen species are toxic to all organisms, ${ }^{2} \mathrm{O}_{2}$ is none-the-less necessary for ATP generation in aerobic cells ${ }^{3}$ and for several other physiological functions. Low $\mathrm{O}_{2}$ concentrations result in hypoxia, which is observed in tumor tissues ${ }^{4}$ due to the fact that cancer cells rapidly consume oxygen as they produce energy via a high rate glycolysis (i.e. the "Warburg Effect"). ${ }^{5}$ Significant efforts have been devoted to develop reliable techniques for the detection of oxygen as $\mathrm{O}_{2}$ levels are indicative of the physiological behavior of living

*Corresponding Author sneep@uic.edu.

Additional spectroscopic and NMR data. This material is available free of charge via the Internet at http://pubs.acs.org.

Author Contributions The manuscript was written through contributions of all authors. / All authors have given approval to the final version of the manuscript. 
systems. Furthermore, the quantification of oxygen is an indispensable part of environmental analysis, food packaging, and industrial monitoring. ${ }^{6}$

Oxygen has a high diffusion rate and a limited temperature-dependent solubility in aqueous solutions. ${ }^{7}$ These properties complicate sampling and necessitate real-time measurements. Various oxygen detection techniques have been reported based on chemical (Winkler titration), ${ }^{8,9}$ electrochemical ${ }^{10}$ (such as the Clark electrode) ${ }^{11}$ and instrumental (GC or MRI ${ }^{12,13}$ methods. Many of these suffer from drawbacks such as relatively long response times or a lack of consistency, accuracy, or reversibility. Worst of all is the potential consumption of oxygen during the detection process. Recently, optical methods have attracted attention since they offer reversible responses with no electrical interferences and generally do not annihilate the analyte. Furthermore, they are inexpensive and easy to miniaturize, and may be used in a relatively noninvasive manner. ${ }^{14-16}$

Semiconductor quantum dots (QDs) are frequently used in bio-analytical techniques due to their highly robust physical properties. While often used for imaging purposes, quantum dots are also valuable components of fluorescent sensing systems for metabolites such as oxygen and $\mathrm{pH}$, etc. ${ }^{17-19}$ Here we report a probe for the in vitro detection of oxygen based on nontoxic near IR-emissive QDs coupled to a novel perylene dye derivative. This platform offers several advantages over other optical reporters. Specially, the use of near-IR emissive quantum dots reduces photobleaching and enhances the signal for through-tissue imaging. We have also avoided incorporating ubiquitous CdSe/ZnS QDs in favor of a cadmium-free $\mathrm{AgInS}_{2} / \mathrm{ZnS}$ nanocrystals to mitigate issues with toxicity. As the supermolecular size and surface passivation of core/shell quantum dots removes their environmental sensitivity, the nanocrystals were conjugated to an oxygen-sensitive perylene dye derivative. The result is an $\mathrm{O}_{2}$ sensor that has a ratiometric fluorescent response that is fully quantitative and eliminates problems with light source fluctuations and emission scattering that are issues with single-response "turn-on" or "turn-off" probes. Finally, we demonstrate that the sensor may be used to detect hypoxia in the cytosol of live HeLA cells.

\section{EXPERIMENTAL SECTION}

\section{Materials and Instrumentation}

Perylene ( $\geq 99.5 \%$ ), N,N'-dicyclohexylcarbodiimide (DCC, 99\%), N-hydroxysuccinimide (98\%), triphenylphosphine (99\%), hydrazine monohydrate ( $29 \%$ ), 1,2-dichloroethane (DCE, $\geq 99 \%$ ), titanium (IV) chloride ( $\mathrm{TiCl}_{4}, \geq 99 \%$ ), xylenes ( $\geq 98.5 \%$ ), diethylene glycol ( $\ 99 \%$ ), trimethylamine (TEA, $\geq 99 \%$ ), ethyl acetate (EtOAc, 99.8\%), dichloromethane (DCM, $299.8 \%)$ and hydrochloric acid ( $\mathrm{HCl}, 37 \%)$ were purchased from Sigma-Aldrich. Sodium sulfate (anhydrous, >99\%), potassium hydroxide ( $285 \%$ ) and tetrahydrofuran (THF, 99.9\%) were purchased from Fisher Chemicals. Succinic anhydride (99\%) was purchased from Acros Organics. Where indicated, solvents were dried using activated molecular sieves (3Å, Sigma-Aldrich). The QD-functionalization reagent methoxypolyethylene glycol 350 carbodiimide (MPEG $350 \mathrm{CD}$ ), ${ }^{20}$ and $40 \%$ octylamine-modified poly(acrylic acid) $(\mathrm{PAA})^{21,22}$ were prepared according to previously published protocols. The precursor $\mathrm{N}_{3}$ $\mathrm{PEG}_{400}$-amine was prepared according to ref. ${ }^{23}$. NMR spectra $\left({ }^{1} \mathrm{H}\right.$ and $\left.{ }^{13} \mathrm{C}\right)$ were recorded on a Bruker Avance DRX 400 NMR spectrometer. UV/vis absorbance spectra were 
measured using a Varian Cary 300 Bio UV/vis spectrophotometer, and fluorescence emission spectra were obtained using a custom-designed Horiba Jobin Yvon FluoroLog spectrophotometer. Oxygen levels in aqueous solutions were measured using SevenGo pro ${ }^{\mathrm{TM}}$ dissolved oxygen meter SG6 with inLab ${ }^{\circledR} 605 \mathrm{O}_{2}$-sensor from Mettler Toledo. HeLa cells (CCL-2) were purchased from American Type Culture Collection. Dulbecco's modified eagle medium (DMEM, 10-014 CV) and 0.25\% trypsin/2.21 mM EDTA were purchased from Corning Cellgro®. MEM non-essential amino acids (11140) and HEPES (15630-080) were purchased from Gibco®. Micropipette preparation glass bottom culture dishes (P50G-1.5-14-F) were purchased from Matek Corporation (Ashlan, MA). XenoworksTM Microinjection Systems, P-1000 pipette puller and borosilicate glass tubes (BF100-78-10) were used for microinjections (Sutter Instruments, Novato, CA).

\section{Perylene-PEGamine}

The synthesis of water-soluble perylene-PEGamine dye is outlined in Scheme 1 and is detailed below. All NMR data are provided in the supporting information in Figures S1-S5.

4-oxo-4-(perylene-3-yl)butanoic acid (1)-Perylene (0.252 g, $1 \mathrm{mmol})$ and succinic anhydride $(0.152 \mathrm{~g}, 1.5 \mathrm{mmol})$ were dissolved in dry DCE $(5 \mathrm{~mL})$. The solution kept stirring under a nitrogen atmosphere and was immersed in an ice bath. A solution of $\mathrm{TiCl}_{4}(0.15 \mathrm{~mL}$, $1.3 \mathrm{mmol}$ ) in $1 \mathrm{~mL}$ of DCE was added dropwise to the solution, and the mixture was stirred overnight at room temperature. The next day the product hydrolyzed by adding dilute $\mathrm{HCl}$ and the precipitate was collected by filtration. The product was extracted into EtOAc (20 $\mathrm{mL})$ and washed with DI water $(3 \times 15 \mathrm{~mL})$. The organic layer was dried over anhydrous $\mathrm{Na}_{2} \mathrm{SO}_{4}$ and the solvent was removed under reduced pressure. The solid brown substance was recrystallized from $25 \mathrm{~mL}$ of xylene after heating to $140{ }^{\circ} \mathrm{C}$. The brown powder was separated by centrifuge and dried under reduced pressure (61\% yield).

4-(perylene-3-yl)butanoic acid (2)—4-oxo-4-(perylene-3-yl)butanoic acid ( $0.177 \mathrm{~g}, 0.5$ $\mathrm{mmol}), \mathrm{KOH}(0.224 \mathrm{~g}, 4 \mathrm{mmol})$, and hydrazine monohydrate $98 \%(0.24 \mathrm{~mL}, 5 \mathrm{mmol}$, warning: highly toxic substance) were dissolved in $5 \mathrm{~mL}$ of diethylene glycol, followed by 90 minutes reflux at $180^{\circ} \mathrm{C}$. After $1.5 \mathrm{~h}$ the excess water and hydrazine were drained from condenser allowing the temperature to rise to $200{ }^{\circ} \mathrm{C}$, and the refluxing was continued overnight. The next day the solution was poured into an ice bath and acidified to $\mathrm{pH} 6$ using $3 \mathrm{M} \mathrm{HCl}$. Then the product was extracted with $20 \mathrm{~mL}$ EtOAc, and washed with DI water $(3 \times 15 \mathrm{~mL})$. The organic layer was dried over anhydrous $\mathrm{Na}_{2} \mathrm{SO}_{4}$ and the solvent was removed under reduced pressure. The product was used for the next step without further purification (70\% yield).

2,5-dioxopyrrolidin-1-yl 4-(perylene-3-yl) butanoate (3)-4-(perylene-3-yl)butanoic acid $(0.102 \mathrm{~g}, 0.3 \mathrm{mmol})$ and $\mathrm{N}$-hydroxysuccinimide $(34.5 \mathrm{mg}, 0.3 \mathrm{mmol})$ were dissolved in dry THF $(10 \mathrm{~mL})$. The mixture was placed in an ice bath and a THF solution $(2 \mathrm{~mL})$ of DCC $(61.9 \mathrm{mg}, 0.3 \mathrm{mmol})$ was added dropwise, followed by stirring overnight at room temperature. The next day the white precipitate (1,3-dicyclohexylurea) was filtered out and the filtrate was subjected to reduced pressure to remove THF, resulting in a solid brown powder. The pure product was recrystallized from EtOH (62\% yield). 
N-poly(ethylene)glycol amine-4-(perylene-3-yl)butanamide (4)-2,5dioxopyrrolidin-1-yl 4-(perylene-3-yl) butanoate (44.9 mg, $0.1 \mathrm{mmol}$ ) and $\mathrm{N}_{3}-\mathrm{PEG}_{400^{-}}$ amine (42.4 mg, $0.1 \mathrm{mmol})$ were dissolved in $5 \mathrm{~mL}$ of dry DCM. $14 \mu \mathrm{L}$ of TEA $(0.1 \mathrm{mmol})$ was added to the solution and it was stirred under nitrogen at room temperature overnight. The next day solvent was removed under reduced pressure and triphenylphosphine $(26.2 \mathrm{mg}$, $0.1 \mathrm{mmol}$ was added, followed by $10 \mathrm{~mL}$ of THF. The mixture was stirred $4 \mathrm{~h}$ at room temperature, after which $0.5 \mathrm{~mL}$ of DI water was added to the mixture and the solution was kept stirring at room temperature overnight. The next day the solvent was removed by reduced pressure and $15 \mathrm{~mL}$ of $1 \mathrm{M} \mathrm{HCl}$ was added to the substance. The aqueous dye solution was filtered to separate the insoluble triphenylphosphine oxide. The filtrate was washed with $\mathrm{Et}_{2} \mathrm{O}(3 \times 15 \mathrm{~mL})$ and then $3 \mathrm{~g}$ of $\mathrm{KOH}$ was added to the solution, followed by extraction of the product with DCM $(6 \times 10 \mathrm{~mL})$. The organic layer was dried over anhydrous $\mathrm{Na}_{2} \mathrm{SO}_{4}$ and was subsequently removed under reduced pressure to obtain pure product in the form of an intense yellow viscous oily liquid (60\% yield).

\section{AgInS $_{2} / \mathrm{ZnS}$ QDs Synthesis and Water Solubilization}

$\mathrm{AgInS}_{2} / \mathrm{ZnS}$ core/shell QDs were synthesized according to previously published protocol. ${ }^{24}$ Approximately $0.5 \mathrm{~g}$ of the crude sample was processed by addition of excess ethanol to induce flocculation. The supernatant was discarded and the precipitate was dried under reduced pressure. Next, $30 \mathrm{mg}$ of amphiphilic $40 \%$ octylamine-modified PAA was added to the QDs followed by $\sim 3 \mathrm{~mL}$ of dry chloroform. The solution was sonicated for several minutes to dissolve the polymer completely. The solvent was removed under reduced pressure and 0.1 M NaoH solution was added to disperse the QDs into water. To remove the excess polymer, the solution was dialyzed to neutrality using Amicon Ultra centrifugal filters (100,000 MWCO) from Millipore.

\section{Perylene-PEGamine Conjugation to QDs}

$\mathrm{AgInS}_{2} / \mathrm{ZnS}$ QDs were activated by adding $10 \mathrm{mg}$ of MPEG 350 carbodiimide to $0.5 \mathrm{~mL}$ of water-solubilized QDs and stirring for $20 \mathrm{~min}$. A solution of perylene-PEGamine (4) dissolved in $\mathrm{pH} 8$ phosphate buffer was prepared and added dropwise to the activated QDs solution until the desired dye emission was achieved. The $\mathrm{pH}$ of the solution was adjusted at 8 by adding phosphate buffer, and it was stirred overnight. The next day the solution was dialyzed using a dialysis tube (Float-A-Lyzer G2, 20 kD MWCO, Spectrum Labs) until all the unconjugated dye eluted out. Despite the fact that the perylene emission overlaps the QD absorption, there was minimal observation of FRET energy transfer, which is consistent with the fact that QDs are poor acceptors to dye donors. ${ }^{25}$

\section{Enzymatic Oxygen Scavenging Titration System}

Two separate experiments were conducted to measure the probe's response to varying $\mathrm{O}_{2}$ levels. In the first, the emission of the probe in Tris-HCL pH 7.4 buffer was measured and compared to the same in a screw top cuvette containing an enzyme mixture composed of glucose $(10 \mathrm{mg} / \mathrm{mL})$, glucose oxidase $(0.5 \mathrm{mg} / \mathrm{mL})$, catalase $(0.08 \mathrm{mg} / \mathrm{mL})$, and ATP (3 $\mathrm{mM}$ ), that was allowed to equilibrate for $20 \mathrm{~min}$. The $\mathrm{O}_{2}$ levels were measured using Mettler Toledo SG6-SevenGo pro ${ }^{\mathrm{TM}}$ dissolved oxygen meter with InLab® $605 \mathrm{O}_{2}$ sensor. The 
oxygen concentration dropped from $6.8 \mathrm{ppm}$ to $0.01 \mathrm{ppm}$, which confirms the efficiency of the oxygen scavenging system. A second experiment was conducted under identical enzymatic conditions with the glucose initially absent. Next, glucose was added in small portions in 20 min intervals, after which time the emission spectrum was recorded. Unfortunately, we are not certain of the absolute $\mathrm{O}_{2}$ concentrations as a result, although we assume that they still span the $\sim 6.8$ to $0.01 \mathrm{ppm}$ range. The excitation wavelength of $425 \mathrm{~nm}$ was chosen to co-excite both chromophores simultaneously in these experiments. The fluorescence responses were quantified by dividing the integrated emission in the visible range (originating from perylene) over the integrated emission in the NIR range (originating from the QD).

\section{Cell Culture}

HeLa cells were maintained in DMEM (+) (DMEM supplemented with 10\% FBS, $1 \times$ MEM non-essential amino acids and $15 \mathrm{mM}$ HEPES) at $37^{\circ} \mathrm{C}$ and $5 \% \mathrm{CO}_{2}$. The cells were passaged with $0.25 \%$ trypsin/2.21 mM EDTA. An MTT assay was performed according to the procedure in Ref. 26 to assess the toxicity of compound 4. Cells were exposed for 30 min to reflect the usage of the dye under experimental conditions.

\section{Microinjection}

HeLa cells were grown to 60-70\% confluency in a glass bottom dish before microinjection and kept in either $19.8 \% \mathrm{O}_{2}$ or $6.9 \% \mathrm{O}_{2}$ for studies under ambient or low-level oxygen conditions, respectively. Micropipettes were prepared by the following parameters: heat, ramp-27; pull, 95; velocity, 27; time, 250; and pressure, 250. Micropipettes were loaded with the sensor solution by capillary action and the solution was injected into the cytosol by using the following microinjector parameters: transfer pressure, $17 \mathrm{hPa}$; injection width, $0.1 \mathrm{sec}$; injection pressure, $200 \mathrm{hPa}$.

\section{Fluorescence Microscopy}

Fluorescence images of the injected cells were acquired after 10 min using an epifluorescence microscope (Axiovert 200, Carl Zeiss, Inc.) equipped with an intensified CCD camera (XR Mega 10-S30CL ICCD, Stanford Photonic Inc.) modified with two LEDs for UV and white light (Prizmatix, Ltd.). All images were obtained with a $63 \times / 1.25$ N.A. EC Plan Neofluar oil-immersion objective (Carl Zeiss, Inc.). G365 nm and $427 \mathrm{~nm}( \pm 5$ ) excitation filters were used to excite quantum dots and dye respectively. Emission filters (775 $\pm 70 \mathrm{~nm}$ and $472 \pm 15 \mathrm{~nm}$ ) were used to separately image and measure quantum dots and dye emission intensities. The same settings were used to acquire images in low and ambient levels of oxygen. All images are dark current corrected. Signal intensity was determined from ROIs in the cytoplasm using the Image J software (v 1.47) package. ${ }^{27}$ Note that the magnitudes of the dye/QD emission ratios from the fluorescence and microscopy experiments do not span the same range of values. This is due to differences in the method of collection, and the wavelength-dependent response of the CCD camera. 


\section{RESULTS AND DISCUSSION}

There have been several reports on the development of QD-organic dye coupled chromophore sensors to create synergistic systems with the robust qualities of quantum dots and the analytical capabilities of organic dyes. As large core/shell QDs are mostly passive to their environment, they must be conjugated to a reporting chromophore to engender a quantifiable optical response to targeted analytes. Species of interest include proteases, ${ }^{28}$ biological thiols, ${ }^{29}$ as well as $\mathrm{pH}^{30}$ and $\mathrm{O}_{2}$ levels as these analytes are associated with cancer. Recently, McLaurin et al. developed a QD-based fluorescent sensor for $\mathrm{O}_{2}$ by conjugating oxygen-sensitive osmium complexes to $\mathrm{CdSe} / \mathrm{ZnS}$ nanocrystals. ${ }^{31}$ They characterized FRET energy transfer from the QD to these ligands and demonstrated oxygendependent ratiometric emission. The benefits of these systems include high two-photon absorption cross sections and QD-to-chromophore FRET. However, osmium-containing compounds can be expensive and toxic, have low emission quantum yields $(\sim 1 \%)$, and the probes did not respond to physiological $\mathrm{O}_{2}$ levels.

As such, the same group later used CdSe/ZnS-palladium(II) porphyrin coupled chromophores to profile oxygen levels in vivo, although the gas was quantified via modulation of the $\mathrm{Pd}(\mathrm{II})$-porphyrin luminescence lifetime rather than emission intensity. ${ }^{32,} 33$ Amelia et al. demonstrated oxygen sensing using CdSe/ZnS QDs functionalized with pyrene, ${ }^{34}$ an organic chromophore with a well-characterized $\mathrm{O}_{2}$ sensitivity ${ }^{35,36}$ and reduced toxicity. ${ }^{37,38}$ However, the design of the system resulted in significant QD quenching and was reported to function only in an organic solvent; clearly this precludes applications in many biological systems.

Our group sought to demonstrate oxygen quantification in a biological system using a fully fluorescence-based approach with a singular non-toxic platform. Analyte-dependent ratiometric emission provides a simple output that can be realized using a coupled chromophore. To this end, we employed $\mathrm{AgInS}_{2} / \mathrm{ZnS}$ quantum dots due to their enhanced photostability, high brightness, and broad absorption spectra that allow for co-excitation of both chromophores (Figure S6). Furthermore, the use of a cadmium-free $\mathrm{AgInS}_{2} / \mathrm{ZnS}$ mitigates toxicity issues and offers advantages such as near-IR photoluminescence and a large Stokes shift that is desirable for in vivo imaging.

The choice of an $\mathrm{O}_{2}$-sensitive chromophore must take into account the dye's photophysical properties that engender oxygen-dependent emission efficiency. We will briefly review the many possibilities here although more detailed information can be found in recently published review papers. ${ }^{14-16,39}$ Optical sensors for $\mathrm{O}_{2}$ can either be either colorometric (absorptive), although luminescence-based reporters are preferred for numerous reasons. They function by collisional quenching of the chromophore's excited state(s) by molecular oxygen ${ }^{40,41}$ as depicted by the Jablonski diagram in Figure 1. Absorption of a photon eventually places the chromophore in the lowest singlet excited state $\mathrm{S}_{1}$. Next, many $\mathrm{O}_{2^{-}}$ sensitive dyes undergo non-radiative intersystem crossing to the lowest excited triplet state $\mathrm{T}_{1}$ followed by phosphorescence emission to the ground state. However, ground triplet state molecular oxygen $\left({ }^{3} \Sigma_{\mathrm{g}}{ }^{-}\right)$can act as an energy acceptor to non-radiatively quench the excited triplet state, ${ }^{42,43}$ resulting in an $\mathrm{O}_{2}$-sensitive phosphorescence intensity. This mechanism is 
commonly observed in organometallic complexes such Pd porphyrins ${ }^{44}$ that have been commercialized for oxygen sensing. ${ }^{45}$ As we wish to avoid such metal complexes, we have examined the use of a chromophore that undergoes oxygen-assisted fluorescence quenching from the excited $S_{1}$ to the $T_{1}$ state. ${ }^{46}$ This mechanism of fluorescence-based sensing is commonly observed in polycyclic aromatic hydrocarbons (PAHs) due to their long-lived singlet excited states, which is necessary to observe diffusional quenching by $\mathrm{O}_{2} \cdot{ }^{47}$

While pyrene is an attractive candidate in this regard, ${ }^{34}$ we wish to avoid UV excitation in cell studies. As such, a larger PAH (perylene) was employed ${ }^{48}$ Perylene dyes can be excited in the visible range, are photostable, ${ }^{49}$ and have high emission quantum yields (0.89-0.99) in the blue-green region. ${ }^{50}$ Unfortunately the commercial availability of perylene dye derivatives is limited. As such, we developed a protocol to synthesize a water-soluble perylene-PEGamine that can be conjugation to aqueous QDs encapsulated with $40 \%$ octylamine-modified poly(acrylic acid). The method is shown in Scheme 1, which was successfully executed to synthesize a water-soluble perylene-PEGamine dye with a quantum yield of $0.68 \pm 0.03$ (Figure S7). ${ }^{51}$ The chromophore was also found to be non-toxic as shown in the results of the MTT assay (Figure S8). It was also found to permeate live cells, which engenders the possibility of using it as a "turn-on" sensor for cellular $\mathrm{O}_{2}$ levels. However, such systems cannot ever be fully quantitative as one cannot distinguish between, for example, low $\mathrm{O}_{2}$ levels in the nucleus of a live cell vs. the inability of the chromophore to bypass the nuclear envelope. This issue is addressed by conjugating the perylene derivative to $\mathrm{AgInS}_{2} / \mathrm{ZnS}$ QDs to allow for the oxygen-insensitive dot emission to act as an internal calibration standard. As such, we can ascertain whether minimal perylene emission from the interior of a live cell is due to high $\mathrm{O}_{2}$ content vs. a low density of delivered coupled chromophores.

The ratiometric QD-dye probe was prepared using neutral carbodiimide coupling reagents and purified by dialysis to remove byproducts any free perylene dye. Next, the probe's response to $\mathrm{O}_{2}$ levels was quantified. This was attempted by a variety of methods, including sparging the solution with nitrogen and the freeze-pump-thaw technique. However, the results were never consistent, likely due to perturbation of the coupled chromophore as QD precipitation was occasionally observed with sparging. As such, we investigated the use of an enzymatic system that offers rapid $\mathrm{O}_{2}$ removal and the ability to maintain the anoxia for long periods of time. One of the most well-established schemes is based on the oxidation of glucose with glucose oxidase. In this ATP-driven process gluconic acid and hydrogen peroxide are produced by the action of glucose oxidase on glucose. Catalase removes the $\mathrm{H}_{2} \mathrm{O}_{2}$ by decomposing it into water and oxygen; note that there is an overall net loss of $\mathrm{O}_{2}$ as shown in equations $1 \& 2$ :

$$
\begin{gathered}
\text { glucose }+\mathrm{O}_{2}+\mathrm{H}_{2} \stackrel{\text { glucoseoxidase }}{\longrightarrow} \text { gluconic acid }+\mathrm{H}_{2} \mathrm{O}_{2} \\
\qquad \mathrm{H}_{2} \mathrm{O}_{2} \stackrel{\text { catalase }}{\longrightarrow} \mathrm{H}_{2} \mathrm{O}+\frac{1}{2} \mathrm{O}_{2}
\end{gathered}
$$


A solution composed of the QD-based oxygen probe, glucose oxidase, catalyse, and ATP was titrated with increasing quantities of a glucose in $20 \mathrm{~min}$ intervals to progressively lower the $\mathrm{O}_{2}$ concentration. The fluorescent response of the sensor shown in Figure 2A was quantified by fitting multiple Gaussian functions to calculate the integrated dye:QD emission ratio. As can be seen in Figure 2B, the dye:QD ratio increased by adding glucose until complete deoxygenation occurred at which point the response was saturated. The overall alteration of the emission ratio is $>100 \%$ over a measured oxygen concentration range of 6.8 to $0.01 \mathrm{ppm}$ as shown in Figure S9. As such, the coupled perylene-QD chromophore can ratiometrically respond to physiologically relevant $\mathrm{O}_{2}$ levels in the visible-to-NIR region of the spectrum.

We investigated the probe response to alterations of oxygen concentration in vitro. As discussed previously, the water-soluble perylene-PEGamine dye is cell permeable; however, the QD-dye conjugate isn't and needed to be microinjected into cells. With this issue resolved, we next investigated several methods to control the oxygen levels in HeLa cells. First, incubation of the cells in the presence of the enzymatic oxygen scavenger system failed due to cell death. As a result, we tried to image the cells immediately after exposure to the enzyme mixture. However, no effect was observed, which we believe is due to the fact that equilibrium in the gas levels was not achieved over the short time interval. Despite these failures, we were able to demonstrate in vitro $\mathrm{O}_{2}$ quantification from two sets of $\mathrm{HeLa}$ cells that were cultured overnight under $6.9 \%$ and $19.8 \% \mathrm{O}_{2}$ concentrations. Next, they were microinjected with the QD-perylene dye, and wavelength-selective microscopic images were obtained of the cells using separate bandpass filters for the QD and dye channels. As shown in Figure 3, there was a 30\% enhancement in the intensity of the dye/QD signal in the hypoxic cells; the detailed changes in the intensities of the QD and dye signals are quantified for 13 different microinjected cells in Table S1 of the supporting information. As such, these control experiments demonstrate the potential use of a QD-perylene dye conjugate for the ratiometric measurement of hypoxia in live cells, which is a biological indicator of cancer.

\section{CONCLUSIONS}

A fluorescent ratiometric oxygen probe was reported based $\mathrm{O}_{2}$ modulation of the fluorescence of perylene dye conjugated oxygen-insensitive near-IR emitting $\mathrm{AgInS}_{2} / \mathrm{ZnS}$ QDs. An enzymatic system composed of glucose, glucose oxidase, catalase and ATP was used to deoxygenate the samples which proved to highly robust and reproducible compared to sparging the solution or the freeze-pump-thaw technique. A $>100 \%$ increase in dye:QD ratiometric signal was observed upon deoxygenation from $\mathrm{ppm}$ to $0.01 \mathrm{ppm}$. In vitro measurement were conducted by microinjection of the probe into live HeLa cells incubated under ambient and hypoxic oxygen levels overnight, which demonstrates the possibility of using this $\mathrm{O}_{2}$ sensor for cancer detection and research.

\section{Supplementary Material}

Refer to Web version on PubMed Central for supplementary material. 


\section{ACKNOWLEDGMENT}

PTS would like to thank support by Colgate-Palmolive, the Chicago Biomedical Consortium with support from the Searle Funds at the Chicago Community Trust, as well as the University of Illinois at Chicago. LWM was supported by the National Institutes of Health (R01GM081030).

Funding Sources Colgate-Palmolive, the Chicago Biomedical Consortium, the National Institutes of Health, and the University of Illinois at Chicago.

\section{ABBREVIATIONS}

EDTA ethylenediaminetetraacetic acid

MEM minimal essential medium

HEPES 4-(2-hydroxyethyl)-1-piperazineethanesulfonic acid.

\section{REFERENCES}

(1). Lane, N. Oxygen: the molecule that made the world. Oxford University Press; Oxford: 2003.

(2). Fenchel T, Finlay B. Oxygen and the Spatial Structure of Microbial Communities. Biol. Rev. 2008; 83:553-569. [PubMed: 18823390]

(3). Jez M, Rozman P, Ivanovic Z, Bas T. Concise Review: The Role of Oxygen in Hematopoietic Stem Cell Physiology. J. Cell. Physiol. 2015; 230:1999-2005. [PubMed: 25655806]

(4). Noman MZ, Hasmim M, Messai Y, Terry S, Kieda C, Janji B, Chouaib S. Hypoxia: A Key Player in Antitumor Immune Response. A Review in the Theme: Cellular Responses to Hypoxia. Am. J. Physiol. Cell Physiol. 2015; 309:C569-579. [PubMed: 26310815]

(5). Thorne JL, Campbell MJ. Nuclear Receptors and the Warburg Effect in Cancer. Int. J. Cancer. 2015; 137:1519-1527. [PubMed: 24895240]

(6). Cichello SA. Oxygen Absorbers in Food Preservation: A Review. J. Food Sci. Technol. 2015; 52:1889-1895. [PubMed: 25829570]

(7). Battino R, Rettich TR, Tominaga T. The Solubility of Oxygen and Ozone in Liquids. J. Phys. Chem. Ref. Data. 1983; 12:163-178.

(8). Helm I, Jalukse L, Leito I. A Highly Accurate Method for Determination of Dissolved Oxygen: Gravimetric Winkler Method. Anal. Chim. Acta. 2012; 741:21-31. [PubMed: 22840701]

(9). Winkler LW. Die Bestimmung Des Im Wasser Gelösten Sauerstoffes. Ber. Dtsch. Chem. Ges. 1888; 21:2843-2854.

(10). Hutton L, Newton ME, Unwin PR, Macpherson JV. Amperometric Oxygen Sensor Based on a Platinum Nanoparticle-Modified Polycrystalline Boron Doped Diamond Disk Electrode. Anal. Chem. 2009; 81:1023-1032. [PubMed: 19117391]

(11). Clark LC Jr. Wolf R, Granger D, Taylor Z. Continuous Recording of Blood Oxygen Tensions by Polarography. J. Appl. Physiol. 1953; 6:189-193. [PubMed: 13096460]

(12). Swinnerton JW, Linnenbom VJ, Cheek CH. Determination of Dissolved Gases in Aqueous Solutions by Gas Chromatography. Anal. Chem. 1962; 34:483-485.

(13). Christen T, Bolar DS, Zaharchuk G. Imaging Brain Oxygenation with MRI Using Blood Oxygenation Approaches: Methods, Validation, and Clinical Applications. AJNR Am. J. Neuroradiol. 2013; 34:1113-1123. [PubMed: 22859287]

(14). Wang XD, Wolfbeis OS. Optical Methods for Sensing and Imaging Oxygen: Materials, Spectroscopies and Applications. Chem. Soc. Rev. 2014; 43:3666-3761. [PubMed: 24638858]

(15). Wang XD, Chen HX, Zhao Y, Chen X, Wang XR, Chen X. Optical Oxygen Sensors Move Towards Colorimetric Determination. TrAC, Trends Anal. Chem. 2010; 29:319-338.

(16). Papkovsky DB, Dmitriev RI. Biological Detection by Optical Oxygen Sensing. Chem. Soc. Rev. 2013; 42:8700-8732. [PubMed: 23775387] 
(17). Petryayeva E, Algar WR, Medintz IL. Quantum Dots in Bioanalysis: A Review of Applications across Various Platforms for Fluorescence Spectroscopy and Imaging. Appl. Spectrosc. 2013; 67:215-252. [PubMed: 23452487]

(18). Silvi S, Credi A. Luminescent Sensors Based on Quantum Dot-Molecule Conjugates. Chem. Soc. Rev. 2015; 44:4275-4289. [PubMed: 25912483]

(19). Stanisavljevic M, Krizkova S, Vaculovicova M, Kizek R, Adam V. Quantum Dots-Fluorescence Resonance Energy Transfer-Based Nanosensors and Their Application. Biosens. Bioelectron. 2015; 74:562-574. [PubMed: 26188679]

(20). Shen H, Jawaid AM, Snee PT. Poly(Ethylene Glycol) Carbodiimide Coupling Reagents for the Biological and Chemical Functionalization of Water-Soluble Nanoparticles. ACS Nano. 2009; 3:915-923. [PubMed: 19275175]

(21). Wu XY, Liu HJ, Liu JQ, Haley KN, Treadway JA, Larson JP, Ge NF, Peale F, Bruchez MP. Immunofluorescent Labeling of Cancer Marker Her2 and Other Cellular Targets with Semiconductor Quantum Dots. Nat. Biotechnol. 2003; 21:41-46. [PubMed: 12459735]

(22). Chen Y, Thakar R, Snee PT. Imparting Nanoparticle Function with Size-Controlled Amphiphilic Polymers. J. Am. Chem. Soc. 2008; 130:3744-3745. [PubMed: 18321112]

(23). Schwabacher AW, Lane JW, Schiesher MW, Leigh KM, Johnson CW. Desymmetrization Reactions: Efficient Preparation of Unsymmetrically Substituted Linker Molecules. J. Org. Chem. 1998; 63:1727-1729.

(24). Shamirian A, Appelbe O, Zhang QB, Ganesh B, Kron SJ, Snee PT. A Toolkit for Bioimaging Using near-Infrared AgInS 2 /ZnS Quantum Dots. J. Mat. Chem. B. 2015; 3:8188-8196.

(25). Clapp AR, Medintz IL, Fisher BR, Anderson GP, Mattoussi H. Can Luminescent Quantum Dots Be Efficient Energy Acceptors with Organic Dye Donors? J. Am. Chem. Soc. 2005; 127:12421250. [PubMed: 15669863]

(26). Rajendran M, Yapici E, Miller LW. Lanthanide-Based Imaging of Protein-Protein Interactions in Live Cells. Inorg. Chem. 2014; 53:1839-1853. [PubMed: 24144069]

(27). Schneider CA, Rasband WS, Eliceiri KW. NIH Image to Imagej: 25 Years of Image Analysis. Nat. Methods. 2012; 9:671-675. [PubMed: 22930834]

(28). Kim GB, Kim YP. Analysis of Protease Activity Using Quantum Dots and Resonance Energy Transfer. Theranostics. 2012; 2:127-138. [PubMed: 22375154]

(29). Shamirian A, Afsari HS, Wu DH, Miller LW, Snee PT. Ratiometric QD-FRET Sensing of Aqueous $\mathrm{H}_{2} \mathrm{~S}$ in Vitro. Anal. Chem. 2016; 88:6050-6056. [PubMed: 27156947]

(30). Snee PT, Somers RC, Nair G, Zimmer JP, Bawendi MG, Nocera DG. A Ratiometric CdSe/ZnS Nanocrystal pH Sensor. J. Am. Chem. Soc. 2006; 128:13320-13321. [PubMed: 17031920]

(31). McLaurin EJ, Greytak AB, Bawendi MG, Nocera DG. Two-Photon Absorbing Nanocrystal Sensors for Ratiometric Detection of Oxygen. J. Am. Chem. Soc. 2009; 131:12994-13001. [PubMed: 19697933]

(32). Lemon CM, Karnas E, Bawendi MG, Nocera DG. Two-Photon Oxygen Sensing with Quantum Dot-Porphyrin Conjugates. Inorg. Chem. 2013; 52:10394-10406. [PubMed: 23978247]

(33). Lemon CM, Karnas E, Han X, Bruns OT, Kempa TJ, Fukumura D, Bawendi MG, Jain RK, Duda DG, Nocera DG. Micelle-Encapsulated Quantum Dot-Porphyrin Assemblies as in vivo TwoPhoton Oxygen Sensors. J. Am. Chem. Soc. 2015; 137:9832-9842. [PubMed: 26149349]

(34). Amelia M, Lavie-Cambot A, McClenaghan ND, Credi A. A Ratiometric Luminescent Oxygen Sensor Based on a Chemically Functionalized Quantum Dot. Chem. Commun. (Camb.). 2011; 47:325-327. [PubMed: 20730204]

(35). Fujiwara Y, Okura I, Miyashita T, Amao Y. Optical Oxygen Sensor Based on Fluorescence Change of Pyrene-1-butyric Acid Chemisorption Film on an Anodic Oxidation Aluminium Plate. Anal. Chim. Acta. 2002; 471:25-32.

(36). Vaugham WM, Weber G. Oxygen Quenching of Pyrenebutyric Acid Fluorescence in Water. A Dynamic Probe of Microenvironment. Biochemistry. 1970; 9:464. [PubMed: 5461215]

(37). Snow TR, Jobsis FF. Characterization of Oxygen Probe Pyrenebutyric Acid in Rabbit HeartMitochondria. Biochim. Biophys. Acta. 1976; 440:36-44. [PubMed: 947363] 
(38). Takeuchi T, Kosuge M, Tadokoro A, Sugiura Y, Nishi M, Kawata M, Sakai N, Matile S, Futaki S. Direct and Rapid Cytosolic Delivery Using Cell-Penetrating Peptides Mediated by Pyrenebutyrate. ACS Chem. Biol. 2006; 1:299-303. [PubMed: 17163758]

(39). Feng Y, Cheng J, Zhou L, Zhou X, Xiang H. Ratiometric Optical Oxygen Sensing: A Review in Respect of Material Design. Analyst. 2012; 137:4885-4901. [PubMed: 22943050]

(40). Lakowicz JR, Weber G. Quenching of Fluorescence by Oxygen. Probe for Structural Fluctuations in Macromolecules. Biochemistry. 1973; 12:4161-4170. [PubMed: 4795686]

(41). Rumsey WL, Vanderkooi JM, Wilson DF. Imaging of Phosphorescence - a Novel Method for Measuring Oxygen Distribution in Perfused Tissue. Science. 1988; 241:1649-1651. [PubMed: 3420417]

(42). Ogilby PR. Singlet Oxygen: There Is Indeed Something New under the Sun. Chem. Soc. Rev. 2010; 39:3181-3209. [PubMed: 20571680]

(43). Krasnovsky AA. Photoluminescence of Singlet Oxygen in Pigment Solutions. Photochem. Photobiol. 1979; 29:29-36.

(44). Lo LW, Koch CJ, Wilson DF. Calibration of Oxygen-Dependent Quenching of the Phosphorescence of Pd-Meso-Tetra (4-Carboxyphenyl) Porphine: A Phosphor with General Application for Measuring Oxygen Concentration in Biological Systems. Anal. Biochem. 1996; 236:153-160. [PubMed: 8619481]

(45). Dunphy I, Vinogradov SA, Wilson DF. Oxyphor R2 and G2: Phosphors for Measuring Oxygen by Oxygen-Dependent Quenching of Phosphorescence. Anal. Biochem. 2002; 310:191-198. [PubMed: 12423638]

(46). Schweitzer C, Schmidt R. Physical Mechanisms of Generation and Deactivation of Singlet Oxygen. Chem. Rev. 2003; 103:1685-1757. [PubMed: 12744692]

(47). Ware WR. Oxygen Quenching of Fluorophores in Solution: An Experimental Study of the Diffusion Process. J. Phys. Chem. 1962; 66:455-458.

(48). Peterson JI, Fitzgerald RV, Buckhold DK. Fiber-Optic Probe for in Vivo Measurement of Oxygen Partial Pressure. Anal. Chem. 1984; 56:62-67. [PubMed: 6696231]

(49). Trofymchuk K, Reisch A, Shulov I, Mely Y, Klymchenko AS. Tuning the Color and Photostability of Perylene Diimides inside Polymer Nanoparticles: Towards Biodegradable Substitutes of Quantum Dots. Nanoscale. 2014; 6:12934-12942. [PubMed: 25233438]

(50). Brouwer AM. Standards for Photoluminescence Quantum Yield Measurements in Solution (IUPAC Technical Report). Pure Appl. Chem. 2011; 83:2213-2228.

(51). Rurack K, Spieles M. Fluorescence Quantum Yields of a Series of Red and near-Infrared Dyes Emitting at 600-1000 nm. Anal. Chem. 2011; 83:1232-1242. [PubMed: 21250654] 


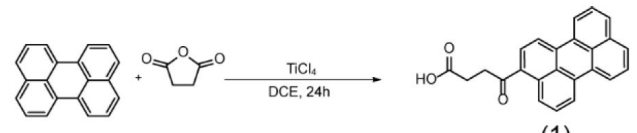

(1)

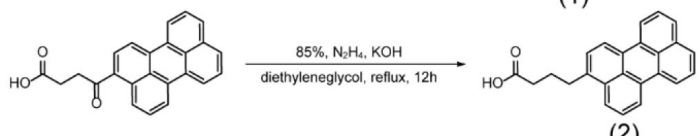

(2)

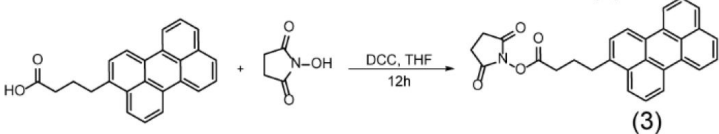

(3)
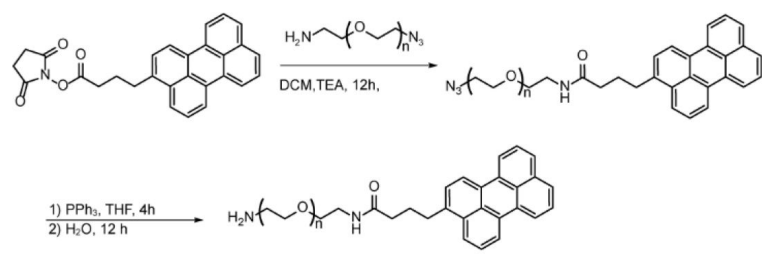

(4)

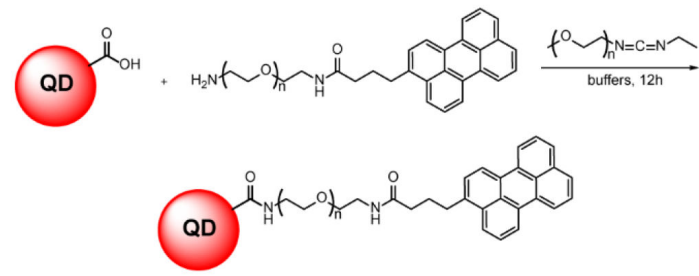

Scheme 1.

Perylene-PEGamine synthesis and conjugation to QDs. 


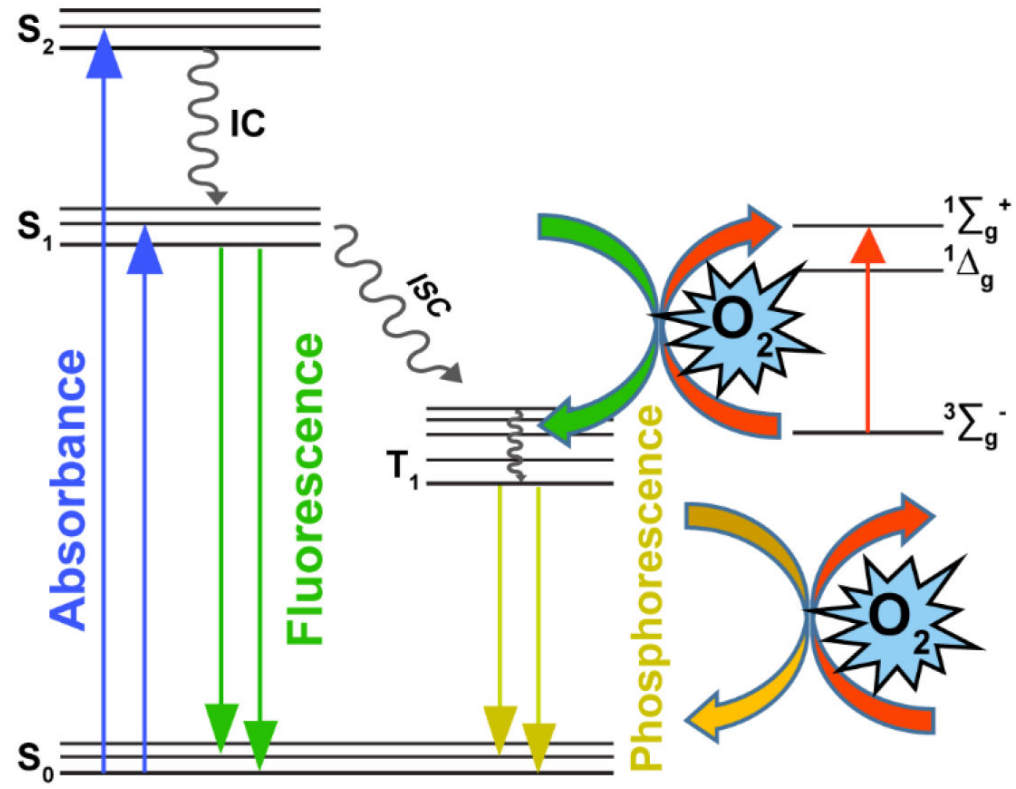

Figure 1.

Jablonski diagram of fluorescence and phosphorescence quenching by molecular $\mathrm{O}_{2}$. This study employs a perylene dye that undergoes fluorescence quenching by oxygen. 

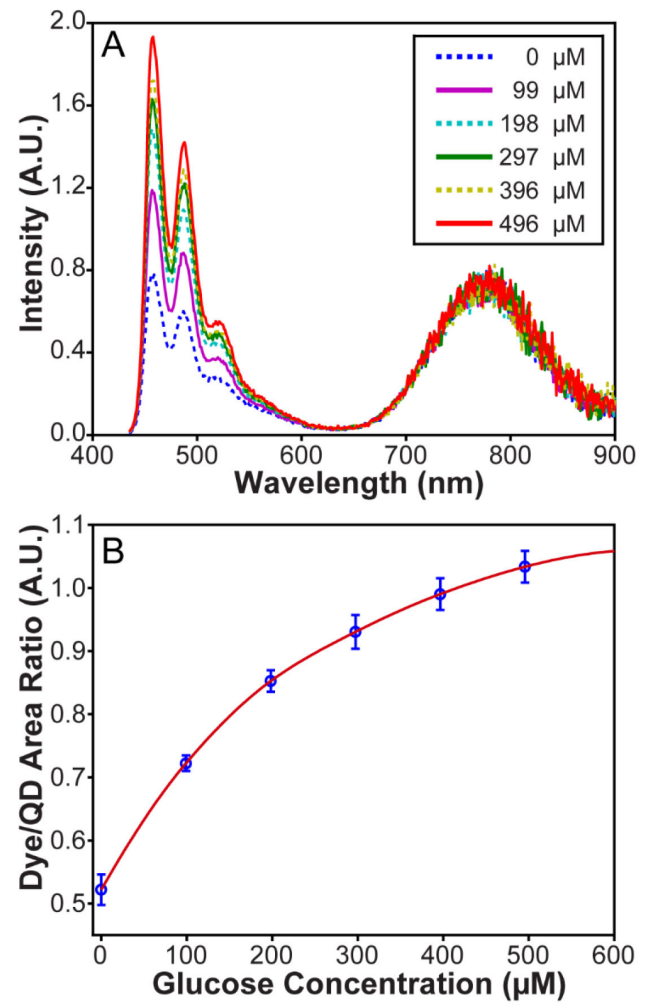

Figure 2.

(a) Emission of the sensor in response to decreasing oxygenation of the solution due to increasing glucose concentration (inset) that is the substrate of an enzymatic oxygen scavenging system. (b) Dye/QD integrated emission ratio in response to the addition of glucose to the enzymatic oxygen scavenging system. 


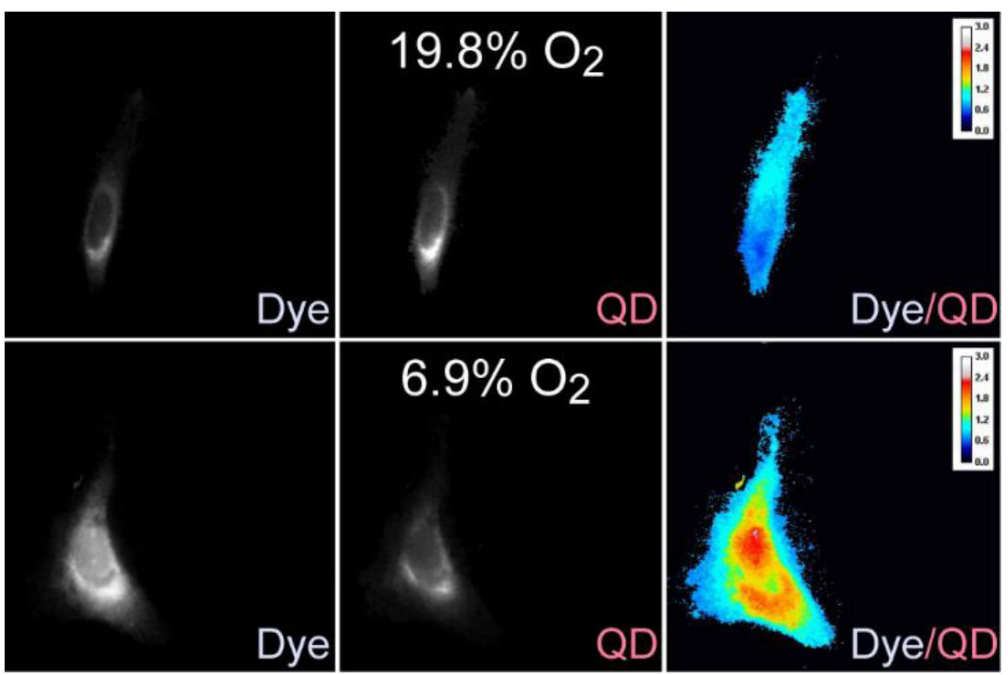

Figure 3.

Ratiometric response of the sensor to hypoxia in HeLa cells incubated under $19.8 \% \mathrm{O}_{2}$ (top row) and hypoxic $6.9 \% \mathrm{O}_{2}$ (bottom row) levels overnight. Emission from perylene dye (472 $\mathrm{nm}$ ) was observed due to visible $427 \mathrm{~nm}$ excitation, while the QD channel was observed at $775 \mathrm{~nm}$ using $365 \mathrm{~nm}$ excitation. 